\title{
VARIATION OF SPECIFIC GRAVITY WITHIN Eucalyptus grandis TREES GROWING IN DIFFERENT SITE CLASSES.
}

\author{
N.D. Ruwanpathirana', H.S. Annarasekara² \& M.P. De Silva ${ }^{3}$ \\ 1 State Timber Corporation, Sampathpaya, Battaramulia \\ 2 Department of Forestry \& Environmental Science, \\ University of Sri jayewardenepura \\ 3Faculty of Science, Jniversity of Ruhuna
}

\begin{abstract}
Wood is a very remarkable material with variability and flexibility. The variability of wood increases its utility. It may be also a major drawback to its efficient use as raw material. Therefore understanding of pattern of wo properties within the tree has become important. In addition, growth rate and its effect on wood properties are of practical importance to maximize wood and fiber production. In this study, variations of specific gravity within the trees of 30-years old Elcalyptus grandis extracted from Pattipola, Santhipura and Piduruthalagala in Nuwara-Eliya districts were studied. Data were collected in relation to site class (growth rate) as determined by tree height. The objective of the study was to find out whether specific gravity is affected by growth rate of tree. Specific gravity values were collected in a systematic manner, which are essential in commercial utilization of this species. Three sites, namely Slow Growth Sitc (SGS), Medium Growth Site (MGS) Fast Growth Site (FGS) were chosen. Five trees from each site wcre taken for the investigation. Tree hijht difference between SGS (33.8 mcters) FGS (45 meters) was significantly different $(\mathrm{P} \leq 0.05)$ but not between SGS and MGS (38 7 meters)
\end{abstract}

Variation patterns of specific gravity in racial direction were studied using two linear sections extracted across the diameter of ever sample disc, from north to south and cast to west at different height levels at breast height and at $20 \%, 40 \%, 60 \%$ and $80 \%$ of total tree height. 3021 wood samples of $2 * 2 * 1 \mathrm{~cm}$ dimensions were used for specific gravity determination.

In general, low specific gravity values were observed at pith in all thrce sites. In fast growth sitc, specific gravity increased from the bark with small fluctuation. In slow and medium growth sites, however specific gravity increased gradually towards the bark. Fast growh site maintained the highest specific gravity values throughout piths to bark. The specific gravity of SGS and MGS increased rapidly with increasing distance from pith.

In general, specific gravity increased with trec leight in all sites except at $20 \%$ height level in SGS and MGS. Mean specific gravity values in SGS at breast height, 20\%, 40\%, 60\% and $80 \%$ height levels were $0.432,0.431,0433,0.468$ and 0.475 respectively. Specific gravity valucs for these levels in MGS were $0.441,0.435,0.467,0.477,0.542$ and Specific gravity values were $0.479,0.482,0.493,0.525,0.553$ for FGS respectively.

Proceedings of the Eighth Annual Forestry and Ervironment Symposium 2002 of the Department of Forestry and Environmental Science, University of Sri Jayewardenepura. Sri Lanka 